\title{
The Innate Immune Response: An Important Partner in Shaping Coxsackievirus-Mediated Autoimmunity
}

\author{
Martin J. Richer Marc S. Horwitz \\ Department of Microbiology and Immunology, The University of British Columbia, Vancouver, B.C., Canada
}

\begin{abstract}
Key Words
Autoimmune myocarditis · Autoimmunity · Coxsackievirus • Innate immunity $\cdot$ Type 1 diabetes
\end{abstract}

\begin{abstract}
To protect against viral infection, the immune response is critically dependent on innate sensing mechanisms to provide rapid detection of pathogens and allow for the development of an appropriate adaptive immune response. Mounting evidence suggests that mechanistic differences in the sensing of viruses by the innate immune response can contribute to the development of autoimmunity. Coxsackieviruses are common human pathogens that have been linked to the induction of autoimmune diseases such as chronic autoimmune myocarditis and type 1 diabetes. In this review, we will discuss the current knowledge of the interactions between coxsackievirus and the innate immune system and how these interactions can potentially lead to the induction of autoimmune diseases.
\end{abstract}

Copyright $\odot 2009$ S. Karger AG, Basel

\section{Introduction}

The innate immune system continually evolves to provide rapid detection of invading pathogens. This innate arm of the immune system provides early protection against infection through the recognition of distinct mo- lecular patterns normally associated with pathogens (pathogen-associated molecular patterns) through a series of germ-line encoded pattern recognition receptors (PRRs). Detection of a pathogen by PRRs initiates signaling cascades leading to the activation of innate mechanisms involved in protecting the host as well as the development of an appropriate adaptive immune response. The activation of a pathogen-specific adaptive response is responsible for complete clearance and development of memory required to prevent subsequent infections. Over the course of most infections, immune regulation mechanisms are sufficient to ensure that the developing immune response is directed at the invading pathogens while minimizing damage to the host. However, in a subset of susceptible hosts, infection can cause a dysregulation of the immune response potentially leading to autoimmunity [1].

Autoimmunity results from an inappropriate immune response directed at self-antigens. This can cause tissue destruction leading to systemic or organ-specific disorders. Although the adaptive immune system, in the form of autoreactive T cells or antibodies, is ultimately responsible for tissue destruction, mounting evidence points to an important role for dysregulated innate immune responses in the etiology of autoimmune diseases particularly following a pathogenic insult. Susceptibility to autoimmune diseases is partially dictated by genetic determinants but several studies have demonstrated that predisposition to some of these diseases can be modified

\section{KARGER \\ Fax +4161306 1234 \\ E-Mail karger@karger.ch}

www.karger.com
(C) 2009 S. Karger AG, Basel

$1662-811 \mathrm{X} / 09 / 0015-0421 \$ 26.00 / 0$

Accessible online at:

www.karger.com/jin
Dr. Marc S. Horwitz

Department of Microbiology and Immunology

The University of British Columbia

3551-2350 Health Sciences Mall, Vancouver, BC, V6T 1Z3 (Canada)

Tel. +1 604822 6298, Fax +1 604822 6041, E-Mail mhorwitz@interchange.ubc.ca 
by a variety of environmental factors including diet, toxins and microbial infections (commensals and pathogens). Among these factors, virus infections have been linked to the induction or exacerbation of both systemic and organ-specific autoimmune diseases including systemic lupus erythematosus [2], myasthenia gravis [3], multiple sclerosis [4], autoimmune myocarditis [5] and type 1 diabetes (T1D) [6]. In recent years, accumulating data has indicated that, more specifically, the interaction of viruses with components of the innate immune system may be responsible for the break in peripheral tolerance that ultimately leads to autoimmunity following infection [7-9]. In this review, we will discuss the role of the innate immune system in viral induction of autoimmunity by focusing on two well-studied autoimmune disorders that have been associated with coxsackievirus infection, autoimmune myocarditis and T1D.

\section{Coxsackievirus-Induced Autoimmunity}

Coxsackieviruses are small, single-stranded RNA viruses classified within the enterovirus genus of the Picornaviridae family [10]. Coxsackievirus infections are typically transmitted in an oral-fecal manner and virus can disseminate to several organs including the pancreas and the heart $[10,11]$. In mouse models, where the virus has been adapted to replicate, viral levels typically peak 2-3 days after infection in the pancreas and 5 days after infection in the heart. By day 15, replicating viruses are not usually detectable, suggesting complete viral clearance [12]. Of particular interest, the group B coxsackievirus (serotypes 1-6) are common human pathogens that are not only associated with mild acute infections but also with more severe acute conditions such as meningitis, encephalitis and pericarditis as well as chronic conditions such as chronic myositis, chronic autoimmune myocarditis, dilated cardiomyopathy and T1D [10]. These viruses have been the subject of intense investigation in order to elucidate the link between viral infection and autoimmunity in both humans and mice.

\section{Coxsackievirus-Induced Autoimmune Myocarditis and Dilated Cardiomyopathy}

Myocarditis is defined as inflammation of the heart muscle and has been well documented to be a leading cause of death among young adults [13]. Several viral pathogens, including coxsackievirus, adenovirus and parvovirus have been associated with the induction of myocarditis. Myocarditis is considered to be a clinical precursor to dilated cardiomyopathy (DCM), a serious medical condition that usually requires heart transplantation [14]. A large proportion of DCM cases reported in the United States have been associated with coxsackievirus infection [15].

Mouse models of myocarditis have been developed to study the pathogenesis of both acute viral-mediated myocarditis and chronic autoimmune myocarditis. Induction of myocarditis following coxsackievirus B3 (CB3) infection has been extensively characterized since heart disease progression following infection with this virus in mice closely resembles disease progression in humans [16]. Heart disease induced following CB3 infection can be separated into two phases with an acute viralmediated phase in the majority of infected hosts followed by a chronic autoimmune phase in genetically susceptible hosts. In mice, acute myocarditis is usually observed 7-14 days after infection due to direct infection and destruction of cardiac tissue by viral particles [17]. Inflammation typically resolves with clearance of the virus by day 15 and normal cardiac function is resumed with little long-term damage occurring. However, in genetically susceptible hosts (the genetics of coxsackievirus induced autoimmune myocarditis have been reviewed elsewhere [18] and will not be the focus of this review) such as A/J, $\mathrm{Balb} / \mathrm{c}$ and non-obese diabetic (NOD) mice, viral clearance is followed by a chronic phase of disease characterized by immune cell infiltration leading to tissue destruction, scarring and deposition of fibrosis [5]. This eventually results in the loss of contractile function, enlargement of the heart and development of DCM [16]. Adoptive transfer experiments have clearly demonstrated that heart damage observed during the chronic phase of disease is immune-mediated and not a direct consequence of viral infection $[19,20]$. Despite the absence of replicative virus at this stage of disease, some groups have reported the presence of viral RNA $[21,22]$ or noncytolytic viral variants [23] long after viral clearance and have suggested that viral persistence may contribute to disease pathogenesis. However, in another model of virus-induced myocarditis, viral genomes have also been recovered at this later stage in mice that are resistant to the development of autoimmune myocarditis, suggesting that viral persistence is not a major contributor to disease progression [16]. Instead, disease susceptibility seems to be directed by several genetic factors leading to a dysregulated immune response following coxsackievirus infection. 


\section{Coxsackievirus-Induced Type 1 Diabetes}

T1D is an autoimmune disorder that results from the specific destruction of the insulin-producing $\beta$ cells of the pancreas. Susceptibility to T1D has been well documented to be dictated in part by genetic determinants. In both humans and mice, a variety of loci have been identified that play roles in the overall susceptibility to disease [24]. Among these are immune genes involved in both the innate and adaptive response [25]. Of particular interest, the candidate genes include a PRR involved in viral recognition, melanoma differentiation-associated gene 5 (mda-5) [26]. Despite this genetic component, the rapid worldwide increase in diabetes incidence [27], the low concordance of disease among identical twins [28] and results from migration studies [29] have strongly suggested that environmental factors are also involved in the etiology of T1D. Several viruses, including rubella, rotavirus and various enteroviruses, have been linked to the induction of T1D [reviewed in 30,31 ] but the strongest evidence linking viruses and T1D comes from studies on coxsackieviruses.

Since the first report of a link between coxsackievirus infections and T1D in the late 1960s [32], several reports, including some from large-scale epidemiological studies, have demonstrated that recent-onset diabetic patients harbor increased levels of coxsackievirus-specific antibodies or coxsackieviral RNA compared to control populations [33-42]. Interestingly, this correlation was also observed in a Cuban study where the incidence of T1D is relatively low and coxsackievirus infections are very prevalent [43]. Most convincingly, coxsackievirus B4 (CB4) has been directly isolated from the pancreas of deceased recent-onset T1D patients [44, 45]. Following isolation, this virus was passaged in murine pancreatic islets and this mouse-adapted strain of CB4 was shown to induce a diabetes-like disease in susceptible mice [44]. Subsequent studies have clearly demonstrated the diabetogenic properties of this viral strain in two mouse models on the NOD (a commonly studied animal model of T1D) genetic background [46, 47]. Therefore, the currently available data strongly suggest that coxsackievirus infections represent an important factor in the etiology of T1D.

Although the mechanisms through which coxsackievirus infection leads to the induction of T1D remain poorly characterized in humans, animal model studies have contributed significantly to our understanding. Studies with the BDC2.5 T cell receptor transgenic model (a NOD-derived transgenic model that does not spon- taneously develop T1D) have demonstrated that induction of disease following CB4 infections is not due to viral-mediated destruction of pancreatic islets or to the induction of virus-specific effector T cells that cross react with pancreatic antigen (molecular mimicry) [47]. Instead, while viral infection of the $\beta$ cells causes minimal cell death, it induces cellular stress leading to the engulfment of the $\beta$ cells by resident antigen-presenting cells (APCs) [48]. This, in turn, leads to the presentation of previously sequestered antigens to a pre-existing population of $\beta$ cell antigen-specific autoreactive $T$ cells in the inflammatory context of a viral infection. Activation of this autoreactive $\mathrm{T}$ cell population leads to the autoimmune destruction of pancreatic $\beta$ cells and subsequently the development of T1D. The induction of T1D following infection in these transgenic mice and in the wild-type NOD model appears to be critically dependent on the presence of a sufficient number of autoreactive $\mathrm{T}$ cells $[46,49]$. A similar mechanism likely occurs in humans as infection of human pancreatic islet cells with enteroviruses has been demonstrated to affect islet function without significant induction of cell death [50]. As such, enteroviral infection of human islets could lead to increased cellular stress, engulfment of $\beta$ cells and presentation of previously sequestered antigens in an inflammatory context. Taken together, this suggests that coxsackievirus infection is able to precipitate an already ongoing autoimmune reaction in susceptible hosts and, as such, may represent the last step in disease progression.

\section{Innate Recognition of Viruses}

Recognition of viral pathogens depends on a series of germ-line-encoded PRRs expressed on cells of the innate immune system such as macrophages and dendritic cells (DCs). Several pathogen-associated molecular patterns linked with viruses can be recognized by PRRs. Among these, viral nucleic acids are sensed by two well-characterized families of PRRs, the Toll-like receptors (TLRs) and the retinoic-acid-inducible gene I-like receptors (RLRs) [51]. A subset of TLRs located within cellular endosomes that include TLR3 (double-stranded RNA), TLR7 (single-stranded RNA), TLR8 (single-stranded RNA, in humans) and TLR9 (unmethylated CpG motifs of DNA) are activated following recognition of common intermediates of viral replication [51]. Similarly, the RLRs (retinoic-acid-inducible gene-I, $5^{\prime}$ triphosphatase moiety on single stranded RNA and mda-5, double stranded RNA) recognize intermediates of viral replication direct- 
ly within the cytoplasm of cells [51]. Additionally, several studies have demonstrated that viral proteins can also serve as pathogen-associated molecular patterns and these are typically recognized by TLRs expressed on the cell surface, particularly TLR2 and TLR4 [51]. The importance of PRRs in the immune response to viruses is now well documented and it is becoming increasingly clear that they are not simply redundant receptors. Instead, they represent an evolutionarily conserved mechanism to recognize the molecular signatures associated with specific viruses as an essential part of a large arsenal of immune defense mechanisms that are tailored for a specific invading pathogen.

Interaction of a PRR with its specific ligand activates signaling cascades with important functional consequences for the developing immune response [for an indepth review on TLR and RLR signaling refer to 52]. Among these is the production of several pro-inflammatory cytokines including type I IFNs. Type I IFNs are pleotropic cytokines that play a crucial role in the early immune response to viruses. Signaling by type I IFNs leads to the establishment of an antiviral state by stimulating the transcription of several IFN-inducible genes that allow for partial control of viral spread through the inhibition of cellular processes that are important for viral replication [53]. Production of type I IFN can also contribute to the activation of natural killer (NK) cells and the maturation of APCs [54]. The production of several other cytokines and chemokines following PRR signaling also serves to enhance innate immune function and further contributes to the development of the viralspecific adaptive immune response [52]. Furthermore, TLR signaling directly contributes to the development of the adaptive immune response by inducing the maturation of APCs that subsequently migrate to the lymph nodes to activate the viral-specific $\mathrm{T}$ and $\mathrm{B}$ cells that are ultimately responsible for clearance of the virus [52]. Recent evidence using MyD88 (an important signaling adaptor required for signaling from every TLR, with the exception of TLR3) or TLR2-deficient mice has further suggested that TLR signaling may directly influence both effector $\mathrm{T}$ cell and regulatory $\mathrm{T}$ cell (Treg) function $[55,56]$. Therefore, PRR recognition of viral pathogens is not only crucial for the early protection of the host by the innate immune response but also exerts a critical influence on the developing adaptive immune response.

Although PRR signaling is clearly important for host defense against viral pathogens, several lines of evidence have also demonstrated that, under certain circumstances, this may be detrimental to the host. In particular,
TLR3 signaling increases the pathogenesis of West Nile virus infection in mice by enhancing the production of cytokines that cause permeabilization of the blood-brain barrier leading to the induction of encephalitis [56]. Similarly, TLR3 deficiency in mice serves to reduce the pathological effects of both influenza virus and Punta Toro virus infections $[57,58]$. Further, as will be discussed below, TLR signaling can contribute to the induction of autoimmunity following viral infection. Taken together, these data demonstrate that inappropriate activation of the innate immune system can have detrimental consequences for the host.

\section{Innate Immune Response to Coxsackievirus}

The innate immune system appears to be critical for the host response to coxsackieviruses. This is best illustrated by experiments demonstrating that severe combined immunodeficient mice lacking both $\mathrm{T}$ and $\mathrm{B}$ cells are able to survive for several weeks following CB4 infection [59]. In vitro experiments have demonstrated that coxsackieviral proteins can be recognized by TLR4 [60] while nucleic acids from these viruses can stimulate cytokine production by signaling through both TLR7 and TLR8 [61]. The relative contribution of these signaling events to the immune response to coxsackievirus remains unclear, however, as our recent data have demonstrated that mice lacking MyD88 (and therefore unable to signal from any TLR except TLR3) do not harbor increased viral titers or present with increased pathology or mortality at early time points following CB4 infection [62]. In addition, MyD88 deficient mice have significantly reduced mortality compared to wild-type mice following CB3 infection [63]. This suggests that MyD88-dependent pathways are not only dispensable for the innate immune response to coxsackieviruses, they may actually be detrimental to the host. Taken together, this indicates that although MyD88-dependent TLRs can recognize coxsackieviruses, MyD88-dependent signaling pathways are not necessary for the immune response to these viruses. Conversely, we demonstrated that TLR3-deficient mice are unable to control viral replication following CB4 infection leading to an increase in cardiac pathology and mortality compared to wild-type mice [62]. This was correlated with decreased production of pro-inflammatory mediators, particularly TNF- $\alpha$ and RANTES (CCL5) suggesting an important role for these molecules in the immune response to coxsackieviruses [62]. These results were confirmed in a separate study demonstrating an im- 
portant role for TLR3 following CB3 infection, although in that model, increased mortality was linked to the inability of TLR3 deficient mice to produce type II IFNs [64]. The importance of RLRs in the detection of coxsackievirus remains unclear, although mda- 5 is known to recognize other picornaviruses and is likely to be involved in the recognition of coxsackieviruses [65]. However, results from TLR3 deficient mice indicate that if the RLR signaling pathway is activated following coxsackievirus infection, it is not sufficient to protect the host [62, 64]. Taken together, this indicates that coxsackieviruses can be recognized by several PRRs that likely contribute to the generation of an appropriate immune response with TLR3 playing a critical non-redundant role.

Several innate effector cell types, including NK cells, macrophages and DCs have been demonstrated to be involved in the immune response to coxsackieviruses [66]. Macrophages, however, seem to play a particularly crucial role in controlling viral replication and reducing tissue pathology following infection. To this effect, it has been demonstrated that inducible nitric oxide synthase (iNOS) expressing macrophages migrate to infected tissues following CB3 infection and that inhibition of this synthase results in increased viral titers [67]. This suggests that nitric oxide production by macrophages is critical for the early control of viral replication. Furthermore, we recently demonstrated that TLR3 signaling on macrophages is sufficient to protect TLR3-deficient mice following infection with $\mathrm{CB} 4$ by reducing cardiac pathology [62]. Interestingly, TLR3-deficient mice produce lower levels of TNF- $\alpha$, an important transcriptional activator of inducible nitric oxide synthase [62,67]. This suggests that TNF- $\alpha$ production following TLR3 signaling may, in part, protect the host from viral infection by inducing the production of nitric oxide from macrophages. Taken together, this indicates that macrophages are central to the innate immune response to coxsackievirus infection.

\section{Innate Immune Mechanisms in Coxsackievirus- Induced Autoimmunity}

The innate response to viral infection plays a pivotal role in directing the ensuing adaptive immune response [68]. As such, the induction of specific innate effector cells can lead to the induction of an autoreactive adaptive immune response with the potential for development of autoimmune pathology. The involvement of innate responses in the development of autoimmunity has been the subject of intense investigation in recent years and in

Innate Immunity and CBV-Induced

Autoimmunity this section we will discuss the data linking innate mechanisms to the induction of autoimmune diseases following coxsackievirus infection.

\section{Pattern Recognition Receptors and the Induction of Autoimmunity by Coxsackieviruses}

Several lines of evidence have demonstrated the importance of PRRs, particularly TLRs, in the pathogenesis of coxsackievirus-induced autoimmune myocarditis. MyD88-deficient mice are unable to signal from the majority of TLRs and are protected from both viral- and adjuvant-induced myocarditis (experimental autoimmune myocarditis, a myocarditis model driven by the injection of cardiac myosin emulsified in complete Freund's adjuvant, this model is commonly used to study the chronic autoimmune phase of myocarditis while removing the complications of an acute viral infection) $[63,69]$. The results of these experiments demonstrated that MyD88 signaling might be involved in several aspects of the pathogenesis of chronic autoimmune myocarditis. MyD88 deficiency reduced inflammation at the sites of infection with a significant reduction in cardiac expression of several cytokines, including both IL-1 $\beta$ and TNF$\alpha$ [63], two cytokines that have long been associated with the induction of autoimmune myocarditis (discussed below and $[70,71])$. Additionally, MyD88 signaling leads to the up-regulation of the coxsackievirus receptor (coxsackie and adenovirus receptor) on cardiac tissue, suggesting that TLR signaling may facilitate cardiac infection [63]. Surprisingly, MyD88-deficient mice produced higher levels of IFN- $\beta$ following infection leading to faster viral clearance suggesting that MyD88-dependent signaling pathways are negative regulators of type 1 interferons [63]. The importance of MyD88 signaling in the chronic phase of myocarditis was further confirmed as MyD88-deficient mice were protected from the induction of experimental autoimmune myocarditis due to the inability of MyD88-deficient APCs to activate autoreactive T cells [69]. A role for MyD88 signaling has also been suggested in humans as DCM patients harbor increased levels of MyD88 mRNA compared to a control population [72]. Combined with the demonstration that MyD88independent pathways are critical for host protection while MyD88-dependent pathways may be dispensable [62], this suggests that therapies aimed at dampening the effects of MyD88 signaling may prove beneficial to patients suffering from coxsackievirus-induced myocarditis.

J Innate Immun 2009;1:421-434 425 
Table 1. Innate immune components in the pathogenesis of coxsackievirus-induced autoimmunity

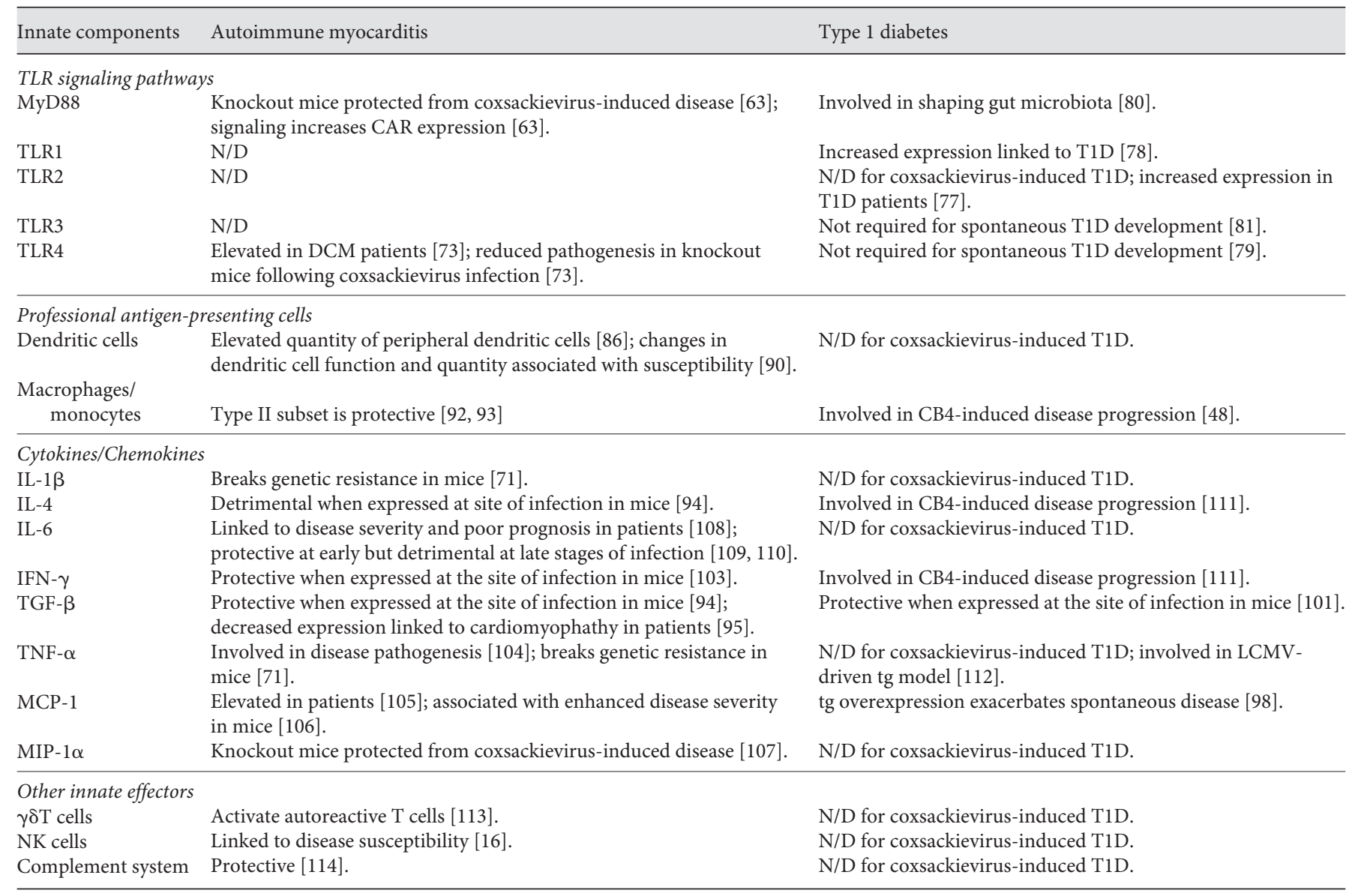

The role of individual TLRs in the induction of autoimmune myocarditis has also been partially elucidated. DCM patients present with elevated mRNA levels for both TLR4 and TLR8 $[72,73]$, two TLRs that have been demonstrated to signal in the presence of coxsackievirus $[60,61]$. Accumulating evidence suggests that TLR4 signaling may be central to the induction of autoimmune myocarditis. The detection of TLR4 mRNA in DCM patients was shown to correlate with enteroviral infection and viral proteins were observed to colocalize with TLR4 in infected cardiac tissue [73]. TLR4 deficiency in mice results in reduced pathogenesis following coxsackievirus infection and this correlates with a reduction in the levels of important cytokines such as IL-1 $\beta$ and IL18 [74]. It has also been suggested that TLR4 signaling increases the capacity of virus to replicate as TLR4-deficient mice harbored lower levels of virus than their wild-type counterparts at day 12 after infection [74]. This is potentially ex- plained by the increased expression of coxsackie and adenovirus receptor mediated by MyD88 signaling [63]. TLR4 has further been linked to the overall susceptibility to disease. In both humans and mice, myocarditis is more common in males compared to females, despite similar prevalence of coxsackievirus infection between genders [75]. In mice, this correlates with increased cardiac expression of TLR4 in males following coxsackievirus infection, suggesting that increased signaling through TLR4 can have adverse effects on the host [75]. Similarly, it has long been described that treatment with lipopolysaccharide (a TLR4 ligand) at the time of coxsackievirus infection is sufficient to break genetic resistance [70]. We have further demonstrated that ligands that signal through TLR4 but not those that signal trough TLR2 are also sufficient to break resistance conferred by transgenic expression of transforming growth factor (TGF)- $\beta$ [76]. This suggests that signaling through TLR4 exerts an 
influence on the susceptibility to autoimmune myocarditis and that differences leading to increased expression or increased signaling from this receptor could represent a significant risk factor for patients. The role of other TLRs and PRRs in the progression of coxsackievirus-induced autoimmune myocarditis remains poorly documented and warrants further investigation.

The role of TLR signaling in the pathogenesis of coxsackievirus-induced T1D is currently not well defined. However, recent evidence indicates that TLR signaling is involved in the development of T1D. Diabetic patients have been observed to harbor increased levels of both TLR2 and TLR4 compared to a nondiabetic control population, suggesting that increased TLR signaling in patients could contribute to pancreatic inflammation [77]. In mice, one of the insulin-dependent diabetes (Idd) susceptibility loci, Idd6, has been demonstrated to control the expression of TLR 1 , and mice congenic for this region expressed lower levels of TLR1 and are protected from T1D development, thus suggesting a role for TLR1 in disease susceptibility [78]. Recent data has demonstrated that both the TLR2 and MyD88 signaling pathways are also involved in the development of T1D in mice $[79,80]$. TLR2 has been proposed to act as a sensor of $\beta$-cell death leading to the maturation of APCs and resulting in the activation of self-reactive T cells [79]. As such, deficiency of TLR2 in NOD mice led to a significant reduction in the incidence of spontaneous T1D [79]. Furthermore, TLR2 has been demonstrated to signal directly within Tregs leading to increased proliferation concomitant with decreased suppressive capacity [56]. This suggests that secondary necrotic $\beta$ cell recognition by TLR 2 may result in decreased immune regulation potentially allowing further activation of autoreactive $\mathrm{T}$ cells and destruction of pancreatic islet cells. MyD88 deficiency was also observed to reduce incidence of T1D although this was attributed to changes in the natural microbial flora of the gut that, in turn, affected the development of autoreactive $\mathrm{T}$ cells [80]. The role of other TLRs in spontaneous development of T1D has also been investigated in mice and it was observed that the TLR9 signaling pathway is involved in disease pathogenesis while both TLR3 and TLR4 do not appear to dictate disease development [79, 81]. Although there is currently little data linking TLRs with coxsackievirus-induced T1D, data from other viral-driven models of T1D suggest that TLRs are likely to be involved. For example, infection of normally resistant biobreeding diabetes resistant rats with the parvovirus Kilham rat virus results in diabetes induction $[82,83]$. The capacity of the virus to induce disease in these rats is dependent in part

Innate Immunity and CBV-Induced Autoimmunity on interactions with TLR9 [84], and TLR3 signaling can synergize with the viral infection to increase susceptibility to disease induction [85]. Based on the importance of TLR3-mediated signals in the immune response to coxsackieviruses [62], it is tempting to speculate that this receptor may be involved in the induction of T1D following coxsackieviral infection. Taken together, this suggests that TLR signaling is involved in the progression of spontaneous T1D and is likely to be involved in the pathogenesis of virus-induced T1D. Whether the same TLRs will be involved in both disease models warrants more investigation.

\section{Antigen-Presenting Cells and the Induction of Autoimmunity by Coxsackieviruses}

One important functional consequence of TLR signaling is the activation and maturation of both macrophages and DCs. This allows for the induction of antiviral mechanisms such as the production of nitric oxide from macrophages, but more importantly it leads to the activation of the adaptive immune system. As such, APCs are likely to be central players in the induction of autoimmunity following infection.

Several lines of evidence point to an important role of APCs in the development of autoimmune myocarditis and DCM. Patients with end-stage heart disease often present with elevated numbers of DCs in the periphery [86]. Furthermore, patients suffering from cardiac inflammation harbor increased numbers of CD11c+ (a DC marker) cells that constitutively express cardiac antigens, suggesting that these DCs may serve to activate autoimmune responses in patients $[87,88]$. The importance of DCs in the pathogenesis of autoimmune myocarditis was clearly supported in a mouse model in which it was demonstrated that adoptive transfer of DCs loaded with a cardiac myosin peptide was sufficient to induce disease in genetically susceptible hosts [89]. Differences in both the function and the number of DCs have further been associated with disease susceptibility in mice. A comparison of the effects of coxsackievirus infection of genetically resistant C57BL/6 mice and genetically susceptible A.BY/SnJ mice revealed that, in response to infection, DCs from susceptible mice produced lower levels of cytokines and chemokines, particularly interferon-inducible protein 10 (IP-10) a chemokine with cardioprotective properties [90]. Furthermore, it was observed that resistant mice harbored significantly more of a particular subset of cross-priming DCs than genetically suscep- 
tible mice [90]. This was correlated with lower virus titers in cardiac tissue of resistant mice suggesting an important role for this cross-priming DC subset in the control of coxsackievirus infection. These results suggest that changes in APC subsets and DC functionality are linked to susceptibility to coxsackievirus-induced myocarditis.

Macrophages play a critical role in the immune response to coxsackievirus and data suggest that they are involved in the pathogenesis of coxsackievirus-induced autoimmune myocarditis. Macrophages are broadly characterized into two groups, type I or type II based on their activation status and cytokine production profile. Alternatively, activated or type II macrophages are typically less inflammatory than classically activated or type I macrophages [91]. Type II macrophages have been ascribed an important role in the healing of cardiac tissue following acute myocardial infarction [92]. Mice deficient for the cytokine IL-13 develop greatly enhanced autoimmune pathology following CB3 infection. This was correlated with a decreased number of alternatively activated macrophages/monocytes compared to wild-type mice [93]. The importance of macrophages was further demonstrated by our studies in a mouse model in which transgenic expression of TGF- $\beta$ protects from the induction of autoimmune myocarditis following CB3 infection [76, 94]. In this model, protection was correlated with reduced maturation of macrophages, suggesting that reducing the inflammatory properties of macrophages may represent a way to prevent disease induction [62]. Interestingly, decreased plasma levels of TGF- $\beta$ have been linked to susceptibility to peripartum cardiomyopathy in patients [95] suggesting that increased maturation of macrophages due to lower levels of TGF- $\beta$ may contribute to heart disease pathogenesis in humans. Taken together, this suggests that the balance between the inflammatory macrophages necessary for the immune response to viruses and alternatively activated macrophages involved in tissue healing and the resolution of the immune response may be critical to the development of an appropriate anti-viral immune response that does not degenerate into autoimmunity.

APCs are also involved in the development and pathogenesis of T1D. In both humans and mice, macrophages and DCs are among the first cell types to infiltrate the pancreatic islets [96]. In the NOD mouse, depletion of macrophages significantly reduces incidence of spontaneous T1D, suggesting an important role for APCs in disease progression [97]. Macrophages have also been proposed to directly contribute to the destruction of pancreatic $\beta$ cells as NOD/Rag knockout mice (lacking $\mathrm{T}$ and $\mathrm{B}$ cells) transgenically expressing the chemokine CCL2 [also known as monocyte chemoattractant protein (MCP)-1] still develop diabetes [98]. This was linked to an increased influx of CCR2+ macrophages/monocytes into the pancreas [98]. The role of APCs in T1D induced following viral infection has been well documented using the BDC2.5 model. In this transgenic mouse model, viral infection leads to the engulfment of pancreatic $\beta$ cells by APCs, and purified APCs from infected mice are sufficient to induce proliferation of autoreactive $\mathrm{BDC} 2.5 \mathrm{~T}$ cells in vitro and to induce disease in uninfected BDC2.5 recipients following adoptive transfer [48]. This suggests that viral infection induces the presentation of previously sequestered antigens leading to the activation of autoreactive $T$ cells and the subsequent destruction of pancreatic $\beta$ cells. Taken together, the evidence currently available indicates that macrophages are likely involved in the induction of T1D following coxsackievirus infection.

Further evidence suggests that changes in macrophage function may also contribute to disease pathogenesis. To this effect, it has recently been demonstrated that monocytes/macrophages are involved in the maintenance of peripheral tolerance and changes within this population may be linked to the development of T1D. Disease progression, in both humans and mice, has been associated with a decline in the capacity of Tregs to maintain peripheral tolerance [99]. Anderson et al. [100] recently demonstrated that CD11b+CD11c- APCs (a population containing a large proportion of monocytes/macrophages) from NOD mice are deficient in the maintenance of the suppressive capacity of Tregs and that this is linked to disease progression. This suggested that deficiencies within the APC compartment rather than a Treg intrinsic defect might be associated with susceptibility to T1D. Interestingly, we recently demonstrated that CB4 infection in the context of TGF- $\beta$ expression is sufficient to protect NOD mice from T1D [101]. This was correlated with changes in the maturation status of this same CD11b+CD11c- APC population and increased levels of Tregs within the pancreas of protected mice [101]. Taken together, this suggests that APCs play a central role in the induction of T1D following viral infection and that therapies aimed at specific APC subsets may be sufficient to prevent autoimmunity following infection and offer an alternative to current therapeutic approaches. To this effect, it was recently shown that glatiramer acetate, a drug commonly used to treat multiple sclerosis patients, works at the lev- 
el of APCs by reducing their maturation levels, reducing production of inflammatory cytokines which, in turn, leads to the induction of Tregs [102] further validating APCs as a target for therapies aimed at preventing autoimmune diseases.

\section{Cytokines and Chemokines in the Induction of Autoimmunity by Coxsackieviruses}

Another important functional consequence of viral detection by the innate immune system is the production of cytokines. Although cytokines are clearly important for the immune response to viruses there is accumulating evidence that they are also involved in the progression and pathogenesis of autoimmune diseases.

Studies using transgenic mice expressing cytokines specifically within the pancreas have demonstrated an important role for the cytokine milieu at the primary site of infection in the progression towards autoimmunity. NOD mice expressing either TGF- $\beta$ or IFN- $\gamma$ under the control of an insulin promoter are protected from the chronic autoimmune phase of myocarditis following CB3 infection without a concomitant protection from the acute phase of disease $[94,103]$. This suggested that the cytokine milieu at the primary site of infection exerts a critical influence on the decision between tolerance and autoimmunity following viral challenge. Cytokine production has also been linked to disease susceptibility. Genetic resistance to autoimmune myocarditis can be overcome by the induction of TNF- $\alpha$ and IL- $1 \beta$ following lipopolysaccharide treatment at the time of CB3 infection [70]. Similarly, direct addition of either one of these cytokines at the time of infection is sufficient to break genetic resistance [71]. Production of TNF- $\alpha$ is also critical for disease progression in genetically susceptible hosts as illustrated by the inability of $\mathrm{CB} 3$ strain $\mathrm{H} 310 \mathrm{~A} 1$ to induce autoimmune myocarditis [104]. This viral strain is capable of infecting and replicating within cardiac tissues but does not induce the TNF- $\alpha$ response normally observed following infection [104]. Convincingly, addition of exogenous TNF- $\alpha$ at the time of infection with this attenuated strain is sufficient to induce autoimmune myocarditis [104]. Taken together, this suggests that TNF- $\alpha$ plays a critical role in the pathogenesis of coxsackievirusinduced autoimmune myocarditis. The effect of TNF- $\alpha$ production on disease progression is likely due to its capacity to induce several downstream molecules. Pro-inflammatory chemokine production can be up-regulated by TNF- $\alpha$, and two of these, MCP-1 (CCL2) and macro-

Innate Immunity and CBV-Induced

Autoimmunity phage inflammatory protein (MIP)-1 $\alpha$, are induced following coxsackievirus infection and have been linked to heart disease. MCP-1 has been found to be elevated in patients suffering from myocarditis and expression levels correlated with disease severity [105]. Similarly, elevated levels of MCP-1 in mice have been associated with increased disease severity due to enhanced migration of CCR2+ monocytes to the heart [106]. Mice lacking macrophage inflammatory protein-1 $\alpha$ do not develop chronic autoimmunity following CB3 infection suggesting an important role for this chemokine in disease progression [107]. Although TNF- $\alpha$ clearly plays a critical role in the development of autoimmunity, any therapies aimed at targeting this molecule will have to take into account the important role that this cytokine also plays in the immune response to viral infection.

The production of other cytokines has been associated with disease progression and studies on their contribution has highlighted that both timing and duration of cytokine expression can exert a critical influence on the development of autoimmunity. One such example is the pleiotropic cytokine IL- 6 that is typically induced following coxsackievirus infection. IL- 6 expression has been linked to increased severity of myocarditis and poor prognosis for patients [108]. Data from experiments on encephalomyocarditis virus-infected mice has revealed that early expression of IL- 6 can serve to reduce cardiac damage [109] while more persistent expression of IL-6 actually leads to increased disease severity [110]. Similarly, data from our laboratory indicates that the absence of IL- 6 results in a dramatic increase in disease severity following CB3 infection and that this correlates with the increased production of inflammatory mediators linked to the progression of myocarditis including TNF- $\alpha$ and MCP-1 [Poffenberger et al., unpubl. observations]. This suggests that early production of IL- 6 is critical to dampen the immune response and protect from the induction of autoimmunity. These results illustrate that the production of cytokines following infection must be tightly regulated at several levels in order to allow for the proper development of a viral-specific immune response without concomitant induction of autoimmunity.

Although the role of specific cytokines and chemokines in the induction of T1D following coxsackievirus infection is currently not as well understood, several lines of evidence suggest that production of inflammatory mediators is involved in disease pathogenesis. Similar to the heart disease model, the cytokine milieu at the primary site of viral infection exerts an influence on disease pro- 
gression. We have recently demonstrated that, in mice, CB4 infection in the context of TGF- $\beta$ leads to protection from the induction of T1D [101]. Interestingly, the presence of TGF- $\beta$ did not affect the capacity of the host to clear the viral infection suggesting that it may be possible to develop therapies that allow for the proper clearance of an invading pathogen while preventing the development of autoimmunity [101]. The production of other cytokines, specifically IFN- $\gamma$ and IL-4, has also been associated with the capacity of coxsackievirus to induce T1D in NOD mice [111]. The production of TNF- $\alpha$ following coxsackievirus infection is also likely to be involved in the pathogenesis of T1D. To this effect, it was demonstrated that, in another model of viral-induced T1D, early production of TNF- $\alpha$ enhanced the incidence of T1D [112]. Interestingly, it was further demonstrated that when production of TNF- $\alpha$ was induced from a transgene later in the course of infection this was sufficient to protect from viral-induced diabetes [112]. This further highlights that the timing of cytokine production may be critical for the induction of autoimmunity following viral infection.

Chemokines are also likely to be involved in the induction of T1D following viral infection. MCP-1 is produced at high levels following coxsackievirus infection and transgenic expression of this chemokine directly within the pancreas significantly increases disease incidence due to its capacity to attract macrophages [98]. This suggests that MCP-1 is likely to be involved in the pathogenesis of coxsackievirus-induced T1D. Cytokines and chemokines induced following viral infection are potentially critical to the induction of T1D by viruses. Research aimed at better understanding the role of these molecules in the immune response to viruses and the progression to autoimmunity may yield new potential therapeutic targets that would allow for the prevention of autoimmune diabetes while maintaining the capacity of the host to respond to viral infections.

\section{Cellular Innate Effectors and the Induction of Autoimmunity following Coxsackievirus Infection}

Several cellular effectors are involved in the induction and pathogenesis of autoimmune diseases following coxsackievirus infection. A particular subset of CD1d-restricted $\gamma \delta$-T cells partially controls viral infection by directly killing infected cells [113]. This same subset of innate $\mathrm{T}$ cells also contributes to the induction of autoimmunity by activating $\mathrm{CD} 4$ helper $\mathrm{T}$ cells that subsequently activate autoreactive CD8 T cells [113]. NK cells are typically involved in the innate immune response to viruses and they have been observed as part of the immune infiltrate in the heart following coxsackievirus infection. Differences in the NK-gene complex between resistant and susceptible strains of mice have been characterized, further linking this cell type to the susceptibility to chronic autoimmune myocarditis [16]. Finally, the complement cascade may be protective against the induction of autoimmunity following viral infection as mice lacking complement receptor 1 and 2 showed faster disease progression and greater disease severity following CB3 infection [114]. Several innate cellular effectors are also likely to be involved in the progression to T1D following infection although this is not currently well characterized. Both NK and NK T cells have been demonstrated to be involved in the development of spontaneous diabetes in NOD mice and they are likely to contribute to disease pathogenesis following viral infection $[115,116]$. Research aimed at better understanding the role of these innate effector cell types in the induction of autoimmune diseases following viral infection should provide important information that, in turn, could lead to the design of better therapeutic approaches.

\section{Concluding Remarks}

Accumulating evidence is clearly indicating that innate mechanisms triggered following viral infection contribute to the induction of autoimmunity in susceptible hosts. Designing therapeutics will require a clear understanding of the innate components that are absolutely required for the immune response directed at the invading pathogens and of the components that may be more involved in the development of autoimmune pathology. Factors such as timing of innate activation and strength of signaling from certain pathways will also need to be considered. In turn this information could be used to design therapeutic approaches that block or dampen innate responses that lead to autoimmunity. For example, in the case of coxsackieviral-induced autoimmunity, MyD88 signaling pathways seem to be heavily involved in the development of autoimmunity following infection while they are dispensable for the early immune responses to viral infection. As such, these pathways may represent interesting therapeutic targets. To this effect, inhibitors of specific TLR pathways have already been reported [117]. Research aimed 
at understanding the contribution of the innate immune response to the development of autoimmunity should also provide invaluable information to help us understand the host-pathogen interactions that ultimately result in immune dysregulation and the induction of autoimmune diseases.

\section{Acknowledgments}

The authors would like to thank S.A. Condotta, M.Sc., A. Olmstead and L.C. Osborne for useful discussion and critical reading of the manuscript. M.S.H. is a scholar of the Michael Smith Foundation for Health Research (MSFHR) and holds a New Investigator award from the Canadian Institutes of Health Research. M.J.R. is a recipient of a John Richard Turner Fellowship.

\section{References}

1 Ercolini AM, Miller SD: The role of infections in autoimmune disease. Clin Exp Immunol 2009;155:1-15.

2 Zandman-Goddard G, Shoenfeld Y: Infections and SLE. Autoimmunity 2005;38:473485.

-3 Lalive PH, Allali G, Truffert A: Myasthenia gravis associated with HTLV-I infection and atypical brain lesions. Muscle Nerve 2007; 35:525-528

-4 Ascherio A, Munger KL: Environmental risk factors for multiple sclerosis. 1. The role of infection. Ann Neurol 2007;61:288-299.

5 Rose NR: Autoimmunity in coxsackievirus infection. Curr Top Microbiol Immunol 2008;323:293-314

6 van der Werf N, Kroese FG, Rozing J, Hillebrands JL: Viral infections as potential triggers of type 1 diabetes. Diabetes Metab Res Rev 2007;23:169-183.

7 Pasare C, Medzhitov R: Toll pathway-dependent blockade of CD4+CD25+ T cell-mediated suppression by dendritic cells. Science 2003;299:1033-1036.

8 Waldner H, Collins M, Kuchroo VK: Activation of antigen-presenting cells by microbial products breaks self tolerance and induces autoimmune disease. J Clin Invest 2004;113: 990-997.

-9 Ichikawa HT, Williams LP, Segal BM: Activation of APCs through CD40 or Toll-like receptor 9 overcomes tolerance and precipitates autoimmune disease. J Immunol 2002; 169:2781-2787.

10 Whitton JL: Immunopathology during coxsackievirus infection. Springer Semin Immunopathol 2002;24:201-213.

11 Huber S, Ramsingh AI: Coxsackievirus-induced pancreatitis. Viral Immunol 2004;17: 358-369.

-12 Wolfgram LJ, Beisel KW, Herskowitz A, Rose NR: Variations in the susceptibility to Coxsackievirus B3-induced myocarditis among different strains of mice. J Immunol 1986; 136:1846-1852.

13 Yusuf S, Reddy S, Ounpuu S, Anand S: Global burden of cardiovascular diseases. 1. General considerations, the epidemiologic transition, risk factors, and impact of urbanization. Circulation 2001;104:2746-2753.
14 Taylor DO, Edwards LB, Aurora P, Christie JD, Dobbels F, Kirk R, Rahmel AO, Kucheryavaya AY, Hertz MI: Registry of the International Society for Heart and Lung Transplantation: twenty-fifth official adult heart transplant report, 2008. J Heart Lung Transplant 2008;27:943-956.

15 Huber SA, Gauntt CJ, Sakkinen P: Enteroviruses and myocarditis: viral pathogenesis through replication, cytokine induction, and immunopathogenicity. Adv Virus Res 1998;51:35-80.

16 Fairweather D, Kaya Z, Shellam GR, Lawson CM, Rose NR: From infection to autoimmunity. J Autoimmun 2001;16:175-186.

17 Esfandiarei M, McManus BM: Molecular biology and pathogenesis of viral myocarditis. Annu Rev Pathol 2008;3:127-155.

18 Li HS, Ligons DL, Rose NR: Genetic complexity of autoimmune myocarditis. Autoimmun Rev 2008;7:168-173.

19 Hashimoto I, Tatsumi M, Nakagawa M: The role of $\mathrm{T}$ lymphocytes in the pathogenesis of Coxsackie virus B3 heart disease. Br J Exp Pathol 1983;64:497-504.

20 Henke A, Huber S, Stelzner A, Whitton JL: The role of CD8+ T lymphocytes in coxsackievirus B3-induced myocarditis. J Virol 1995;69:6720-6728

21 Why HJ, Meany BT, Richardson PJ, Olsen EG, Bowles NE, Cunningham L, Freeke CA, Archard LC: Clinical and prognostic significance of detection of enteroviral RNA in the myocardium of patients with myocarditis or dilated cardiomyopathy. Circulation 1994; 89:2582-2589.

22 Pauschinger M, Doerner A, Kuehl U, Schwimmbeck PL, Poller W, Kandolf R, Schultheiss HP: Enteroviral RNA replication in the myocardium of patients with left ventricular dysfunction and clinically suspected myocarditis. Circulation 1999;99:889-895.

23 Kim KS, Tracy S, Tapprich W, Bailey J, Lee CK, Kim K, Barry WH, Chapman NM: 5'Terminal deletions occur in coxsackievirus B3 during replication in murine hearts and cardiac myocyte cultures and correlate with encapsidation of negative-strand viral RNA. J Virol 2005;79:7024-7041.
24 Hill NJ, King C, Flodstrom-Tullberg M: Recent acquisitions on the genetic basis of autoimmune disease. Front Biosci 2008;13: 4838-4851.

25 Jahromi MM, Eisenbarth GS: Genetic determinants of type 1 diabetes across populations. Ann NY Acad Sci 2006;1079:289299.

26 Smyth DJ, Cooper JD, Bailey R, Field S, Burren O, Smink LJ, Guja C, Ionescu-Tirgoviste C, Widmer B, Dunger DB, Savage DA, Walker NM, Clayton DG, Todd JA: A genomewide association study of nonsynonymous SNPs identifies a type 1 diabetes locus in the interferon-induced helicase (IFIH1) region. Nat Genet 2006;38:617-619.

27 Gale EA: The rise of childhood type 1 diabetes in the 20th century. Diabetes 2002;51: 3353-3361.

28 Hyttinen V, Kaprio J, Kinnunen L, Koskenvuo $\mathrm{M}$, Tuomilehto J: Genetic liability of type 1 diabetes and the onset age among 22,650 young Finnish twin pairs: a nationwide follow-up study. Diabetes 2003;52:1052-1055.

29 Raymond NT, Jones JR, Swift PG, Davies MJ, Lawrence G, McNally PG, Burden ML, Gregory R, Burden AC, Botha JL: Comparative incidence of type I diabetes in children aged under 15 years from South Asian and white or other ethnic backgrounds in Leicestershire, UK, 1989 to 1998. Diabetologia 2001; 44 suppl 3:B32-B36.

30 Jun HS, Yoon JW: A new look at viruses in type 1 diabetes. Diabetes Metab Res Rev 2003;19:8-31.

-31 Richer MJ, Horwitz MS: Viral infections in the pathogenesis of autoimmune diseases: focus on type 1 diabetes. Front Biosci 2008; 13:4241-4257.

32 Gamble DR, Kinsley ML, FitzGerald MG, Bolton R, Taylor KW: Viral antibodies in diabetes mellitus. Br Med J 1969;3:627-630.

33 King ML, Shaikh A, Bidwell D, Voller A, Banatvala JE: Coxsackie-B-virus-specific IgM responses in children with insulin-dependent (juvenile-onset; type I) diabetes mellitus. Lancet 1983;1:1397-1399. 
- 34 Banatvala JE, Bryant J, Schernthaner G, Borkenstein M, Schober E, Brown D, De Silva LM, Menser MA, Silink M: Coxsackie B, mumps, rubella, and cytomegalovirus specific IgM responses in patients with juvenileonset insulin-dependent diabetes mellitus in Britain, Austria, and Australia. Lancet 1985; 1:1409-1412.

- 35 Frisk G, Friman G, Tuvemo T, Fohlman J, Diderholm H: Coxsackie B virus IgM in children at onset of type 1 (insulin-dependent) diabetes mellitus: evidence for IgM induction by a recent or current infection. Diabetologia 1992;35:249-253.

- 36 Clements GB, Galbraith DN, Taylor KW: Coxsackie $B$ virus infection and onset of childhood diabetes. Lancet 1995;346:221223.

- 37 Helfand RF, Gary HE Jr, Freeman CY, Anderson LJ, Pallansch MA: Serologic evidence of an association between enteroviruses and the onset of type 1 diabetes mellitus. Pittsburgh Diabetes Research Group. J Infect Dis 1995;172:1206-1211.

- 38 Andreoletti L, Hober D, Hober-Vandenberghe C, Belaich S, Vantyghem MC, Lefebvre J, Wattre P: Detection of coxsackie B virus RNA sequences in whole blood samples from adult patients at the onset of type I diabetes mellitus. J Med Virol 1997;52:121-127.

- 39 Lonnrot M, Korpela K, Knip M, Ilonen J, Simell O, Korhonen S, Savola K, Muona P, Simell T, Koskela P, Hyoty H: Enterovirus infection as a risk factor for beta-cell autoimmunity in a prospectively observed birth cohort: the Finnish Diabetes Prediction and Prevention Study. Diabetes 2000;49:13141318.

-40 Lonnrot M, Salminen K, Knip M, Savola K, Kulmala P, Leinikki P, Hyypia T, Akerblom $\mathrm{HK}$, Hyoty H: Enterovirus RNA in serum is a risk factor for beta-cell autoimmunity and clinical type 1 diabetes: a prospective study. Childhood Diabetes in Finland (DiMe) Study Group. J Med Virol 2000;61:214-220.

-41 Sadeharju K, Lonnrot M, Kimpimaki T, Savola K, Erkkila S, Kalliokoski T, Savolainen P, Koskela P, Ilonen J, Simell O, Knip M, Hyoty H: Enterovirus antibody levels during the first two years of life in prediabetic autoantibody-positive children. Diabetologia 2001;44:818-823.

-42 Sadeharju K, Hamalainen AM, Knip M, Lonnrot M, Koskela P, Virtanen SM, Ilonen J, Akerblom HK, Hyoty H: Enterovirus infections as a risk factor for type I diabetes: virus analyses in a dietary intervention trial. Clin Exp Immunol 2003;132:271-277.

-43 Sarmiento L, Cabrera-Rode E, Lekuleni L, Cuba I, Molina G, Fonseca M, Heng-Hung L, Borroto AD, Gonzalez P, Mas-Lago P, DiazHorta O: Occurrence of enterovirus RNA in serum of children with newly diagnosed type 1 diabetes and islet cell autoantibodypositive subjects in a population with a low incidence of type 1 diabetes. Autoimmunity 2007;40:540-545.
4 Yoon JW, Austin M, Onodera T, Notkins AL: Isolation of a virus from the pancreas of a child with diabetic ketoacidosis. N Engl J Med 1979;300:1173-1179.

-45 Dotta F, Censini S, van Halteren AG, Marselli L, Masini M, Dionisi S, Mosca F, Boggi U, Muda AO, Prato SD, Elliott JF, Covacci A, Rappuoli R, Roep BO, Marchetti P: Coxsackie $\mathrm{B} 4$ virus infection of beta cells and natural killer cell insulitis in recent-onset type 1 diabetic patients. Proc Natl Acad Sci USA 2007; 104:5115-5120.

-46 Serreze DV, Ottendorfer EW, Ellis TM, Gauntt CJ, Atkinson MA: Acceleration of type 1 diabetes by a coxsackievirus infection requires a preexisting critical mass of autoreactive T-cells in pancreatic islets. Diabetes 2000;49:708-711.

47 Horwitz MS, Bradley LM, Harbertson J, Krahl T, Lee J, Sarvetnick N: Diabetes induced by Coxsackie virus: initiation by bystander damage and not molecular mimicry. Nat Med 1998;4:781-785.

48 Horwitz MS, Ilic A, Fine C, Balasa B, Sarvetnick N: Coxsackieviral-mediated diabetes: induction requires antigen-presenting cells and is accompanied by phagocytosis of beta cells. Clin Immunol 2004;110:134-144.

49 Horwitz MS, Fine C, Ilic A, Sarvetnick N: Requirements for viral-mediated autoimmune diabetes: beta-cell damage and immune infiltration. J Autoimmun 2001;16:211-217.

50 Elshebani A, Olsson A, Westman J, Tuvemo T, Korsgren O, Frisk G: Effects on isolated human pancreatic islet cells after infection with strains of enterovirus isolated at clinical presentation of type 1 diabetes. Virus Res 2007;124:193-203.

51 Bowie AG, Unterholzner L: Viral evasion and subversion of pattern-recognition receptor signalling. Nat Rev Immunol 2008;8: 911-922.

52 Kawai T, Akira S: Toll-like receptor and RIGI-like receptor signaling. Ann N Y Acad Sci 2008;1143:1-20.

53 Sadler AJ, Williams BR: Interferon-inducible antiviral effectors. Nat Rev Immunol 2008;8:559-568.

54 Theofilopoulos AN, Baccala R, Beutler B, Kono DH: Type I interferons (alpha/beta) in immunity and autoimmunity. Annu Rev Immunol 2005;23:307-336.

55 Zhou S, Kurt-Jones EA, Cerny AM, Chan M, Bronson RT, Finberg RW: MyD88 intrinsically regulates CD4 T-cell responses. J Virol 2009;83:1625-1634.

56 Sutmuller RP, den Brok MH, Kramer M, Bennink EJ, Toonen LW, Kullberg BJ, Joosten LA, Akira S, Netea MG, Adema GJ: Toll-like receptor 2 controls expansion and function of regulatory T cells. J Clin Invest 2006;116: 485-494.
57 Le Goffic R, Balloy V, Lagranderie M, Alexopoulou L, Escriou N, Flavell R, Chignard M, Si-Tahar M: Detrimental contribution of the Toll-like receptor (TLR)3 to influenza A virus-induced acute pneumonia. PLoS Pathog 2006;2:e53.

58 Gowen BB, Hoopes JD, Wong MH, Jung KH, Isakson KC, Alexopoulou L, Flavell RA, Sidwell RW: TLR3 deletion limits mortality and disease severity due to Phlebovirus infection. J Immunol 2006;177:6301-6307.

59 Horwitz MS, Krahl T, Fine C, Lee J, Sarvetnick N: Protection from lethal coxsackievirus-induced pancreatitis by expression of gamma interferon. J Virol 1999;73:17561766.

60 Triantafilou K, Triantafilou M: Coxsackievirus $\mathrm{B} 4$-induced cytokine production in pancreatic cells is mediated through toll-like receptor 4. J Virol 2004;78:11313-11320.

-61 Triantafilou K, Orthopoulos G, Vakakis E, Ahmed MA, Golenbock DT, Lepper PM, Triantafilou M: Human cardiac inflammatory responses triggered by Coxsackie B viruses are mainly Toll-like receptor (TLR) 8 -dependent. Cell Microbiol 2005;7:1117-1126.

62 Richer MJ, Lavallee DJ, Shanina I, Horwitz MS: Toll-like receptor 3 signaling on macrophages is required for survival following coxsackievirus B4 infection. PLoS ONE 2009;4:e4127.

63 Fuse K, Chan G, Liu Y, Gudgeon P, Husain M, Chen M, Yeh WC, Akira S, Liu PP: Myeloid differentiation factor- 88 plays a crucial role in the pathogenesis of Coxsackievirus B3-induced myocarditis and influences type I interferon production. Circulation 2005; 112:2276-2285.

64 Negishi H, Osawa T, Ogami K, Ouyang X, Sakaguchi S, Koshiba R, Yanai H, Seko Y, Shitara H, Bishop K, Yonekawa H, Tamura T, Kaisho T, Taya C, Taniguchi T, Honda K: A critical link between Toll-like receptor 3 and type II interferon signaling pathways in antiviral innate immunity. Proc Natl Acad Sci USA 2008;105:20446-20451.

65 Gitlin L, Barchet W, Gilfillan S, Cella M, Beutler B, Flavell RA, Diamond MS, Colonna M: Essential role of mda-5 in type I IFN responses to polyriboinosinic:polyribocytidylic acid and encephalomyocarditis picornavirus. Proc Natl Acad Sci USA 2006;103: 8459-8464.

66 Huber S: Host immune responses to coxsackievirus B3. Curr Top Microbiol Immunol 2008;323:199-221.

67 Lowenstein CJ, Hill SL, Lafond-Walker A, Wu J, Allen G, Landavere M, Rose NR, Herskowitz A: Nitric oxide inhibits viral replication in murine myocarditis. J Clin Invest 1996;97:1837-1843.

68 Pasare C, Medzhitov R: Toll-like receptors: linking innate and adaptive immunity. Microbes Infect 2004;6:1382-1387. 
69 Marty RR, Dirnhofer S, Mauermann N, Schweikert S, Akira S, Hunziker L, Penninger JM, Eriksson U: MyD88 signaling controls autoimmune myocarditis induction. Circulation 2006;113:258-265.

-70 Lane JR, Neumann DA, Lafond-Walker A, Herskowitz A, Rose NR: LPS promotes CB3induced myocarditis in resistant B10.A mice. Cell Immunol 1991;136:219-233.

-71 Lane JR, Neumann DA, Lafond-Walker A, Herskowitz A, Rose NR: Interleukin 1 or tumor necrosis factor can promote Coxsackie B3-induced myocarditis in resistant B10.A mice. J Exp Med 1992;175:1123-1129.

-72 Satoh M, Akatsu T, Ishikawa Y, Minami Y, Takahashi Y, Nakamura M: Association between toll-like receptor 8 expression and adverse clinical outcomes in patients with enterovirus-associated dilated cardiomyopathy. Am Heart J 2007;154:581-588.

-73 Satoh M, Nakamura M, Akatsu T, Shimoda Y, Segawa I, Hiramori K: Toll-like receptor 4 is expressed with enteroviral replication in myocardium from patients with dilated cardiomyopathy. Lab Invest 2004;84:173-181.

-74 Fairweather D, Yusung S, Frisancho S, Barrett M, Gatewood S, Steele R, Rose NR: IL-12 receptor beta 1 and Toll-like receptor 4 increase IL-1 beta-and IL-18-associated myocarditis and coxsackievirus replication. J Immunol 2003;170:4731-4737.

75 Frisancho-Kiss S, Davis SE, Nyland JF, Frisancho JA, Cihakova D, Barrett MA, Rose NR, Fairweather D: Cutting edge: cross-regulation by TLR 4 and T cell Ig mucin-3 determines sex differences in inflammatory heart disease. J Immunol 2007;178:6710-6714.

-76 Richer MJ, Fang D, Shanina I, Horwitz MS: Toll-like receptor 4-induced cytokine production circumvents protection conferred by TGF-beta in coxsackievirus-mediated autoimmune myocarditis. Clin Immunol 2006; 121:339-349.

-77 Devaraj S, Dasu MR, Rockwood J, Winter W, Griffen SC, Jialal I: Increased toll-like receptor (TLR) 2 and TLR4 expression in monocytes from patients with type 1 diabetes: further evidence of a proinflammatory state. J Clin Endocrinol Metab 2008;93:578-583.

78 Vallois D, Grimm CH, Avner P, Boitard C, Rogner UC: The type 1 diabetes locus Idd6 controls TLR1 expression. J Immunol 2007; 179:3896-3903.

-79 Kim HS, Han MS, Chung KW, Kim S, Kim E, Kim MJ, Jang E, Lee HA, Youn J, Akira S, Lee MS: Toll-like receptor 2 senses beta-cell death and contributes to the initiation of autoimmune diabetes. Immunity 2007;27:321333.

80 Wen L, Ley RE, Volchkov PY, Stranges PB, Avanesyan L, Stonebraker AC, Hu C, Wong FS, Szot GL, Bluestone JA, Gordon JI, Chervonsky AV: Innate immunity and intestinal microbiota in the development of Type 1 diabetes. Nature 2008;455:1109-1113.
81 Wong FS, Hu C, Zhang L, Du W, Alexopoulou L, Flavell RA, Wen L: The role of Toll-like receptors 3 and 9 in the development of autoimmune diabetes in NOD mice. Ann NY Acad Sci 2008;1150:146-148.

82 Guberski DL, Thomas VA, Shek WR, Like AA, Handler ES, Rossini AA, Wallace JE, Welsh RM: Induction of type I diabetes by Kilham's rat virus in diabetes-resistant BB/ Wor rats. Science 1991;254:1010-1013.

83 Brown DW, Welsh RM, Like AA: Infection of peripancreatic lymph nodes but not islets precedes Kilham rat virus-induced diabetes in BB/Wor rats. J Virol 1993;67:5873-5878.

84 Zipris D, Lien E, Nair A, Xie JX, Greiner DL, Mordes JP, Rossini AA: TLR9-signaling pathways are involved in Kilham rat virusinduced autoimmune diabetes in the biobreeding diabetes-resistant rat. J Immunol 2007;178:693-701.

85 Zipris D, Lien E, Xie JX, Greiner DL, Mordes JP, Rossini AA: TLR activation synergizes with Kilham rat virus infection to induce diabetes in BBDR rats. J Immunol 2005; 174 : 131-142.

86 Athanassopoulos P, Vaessen LM, Maat AP, Balk AH, Weimar W, Bogers AJ: Peripheral blood dendritic cells in human end-stage heart failure and the early post-transplant period: evidence for systemic Th1 immune responses. Eur J Cardiothorac Surg 2004;25: 619-626.

87 Smith SC, Allen PM: Expression of myosinclass II major histocompatibility complexes in the normal myocardium occurs before induction of autoimmune myocarditis. Proc Natl Acad Sci USA 1992;89:9131-9135.

88 Donermeyer DL, Beisel KW, Allen PM, Smith SC: Myocarditis-inducing epitope of myosin binds constitutively and stably to IAk on antigen-presenting cells in the heart. J Exp Med 1995;182:1291-1300.

89 Eriksson U, Ricci R, Hunziker L, Kurrer MO, Oudit GY, Watts TH, Sonderegger I, Bachmaier K, Kopf M, Penninger JM: Dendritic cell-induced autoimmune heart failure requires cooperation between adaptive and innate immunity. Nat Med 2003;9:1484-1490.

90 Weinzierl AO, Szalay G, Wolburg H, Sauter M, Rammensee HG, Kandolf R, Stevanovic $S$, Klingel K: Effective chemokine secretion by dendritic cells and expansion of crosspresenting CD4-/CD8+ dendritic cells define a protective phenotype in the mouse model of coxsackievirus myocarditis. J Virol 2008;82:8149-8160.

91 Martinez FO, Sica A, Mantovani A, Locati M: Macrophage activation and polarization. Front Biosci 2008;13:453-461.

92 Nahrendorf M, Swirski FK, Aikawa E, Stangenberg L, Wurdinger T, Figueiredo JL, Libby $\mathrm{P}$, Weissleder R, Pittet MJ: The healing myocardium sequentially mobilizes two monocyte subsets with divergent and complementary functions. J Exp Med 2007;204: 3037-3047.
-93 Cihakova D, Barin JG, Afanasyeva M, Kimura M, Fairweather D, Berg M, Talor MV, Baldeviano GC, Frisancho S, Gabrielson K, Bedja D, Rose NR: Interleukin-13 protects against experimental autoimmune myocarditis by regulating macrophage differentiation. Am J Pathol 2008;172:11951208.

94 Horwitz MS, Knudsen M, Ilic A, Fine C, Sarvetnick N: Transforming growth factorbeta inhibits coxsackievirus-mediated autoimmune myocarditis. Viral Immunol 2006; 19:722-733.

95 Ellis JE, Ansari AA, Fett JD, Carraway RD, Randall HW, Mosunjac MI, Sundstrom JB: Inhibition of progenitor dendritic cell maturation by plasma from patients with peripartum cardiomyopathy: role in pregnancy-associated heart disease. Clin Dev Immunol 2005; 12:265-273.

96 Shinomiya M, Nadano S, Shinomiya $H$ Onji M: In situ characterization of dendritic cells occurring in the islets of nonobese diabetic mice during the development of insulitis. Pancreas 2000;20:290-296.

-97 Jun HS, Yoon CS, Zbytnuik L, van Rooijen N, Yoon JW: The role of macrophages in T cell-mediated autoimmune diabetes in nonobese diabetic mice. J Exp Med 1999; 189:347-358.

$\checkmark 98$ Martin AP, Rankin S, Pitchford S, Charo IF Furtado GC, Lira SA: Increased expression of CCL2 in insulin-producing cells of transgenic mice promotes mobilization of myeloid cells from the bone marrow, marked insulitis, and diabetes. Diabetes 2008;57: 3025-3033.

99 Walker LS: Natural Treg in autoimmune diabetes: all present and correct? Expert Opin Biol Ther 2008;8:1691-1703.

100 Anderson AC, Chandwaskar R, Lee DH, Kuchroo VK: Cutting edge: the Idd3 genetic interval determines regulatory $\mathrm{T}$ cell function through CD11b+CD11c- APC. J Immunol 2008;181:7449-7452.

101 Richer MJ, Straka N, Fang D, Shanina I, Horwitz MS: Regulatory T-cells protect from type 1 diabetes after induction by coxsackievirus infection in the context of transforming growth factor-beta. Diabetes 2008;57:1302-1311.

102 Weber MS, Prod'homme T, Youssef S, Dunn SE, Rundle CD, Lee L, Patarroyo JC, Stuve O, Sobel RA, Steinman L, Zamvil SS: Type II monocytes modulate T cell-mediated central nervous system autoimmune disease. Nat Med 2007;13:935-943.

103 Horwitz MS, La Cava A, Fine C, Rodriguez E, Ilic A, Sarvetnick N: Pancreatic expression of interferon-gamma protects mice from lethal coxsackievirus B3 infection and subsequent myocarditis. Nat Med 2000;6: 693-697. 
104 Huber SA, Feldman AM, Sartini D: Coxsackievirus B3 induces $\mathrm{T}$ regulatory cells, which inhibit cardiomyopathy in tumor necrosis factor-alpha transgenic mice. Circ Res 2006;99:1109-1116.

105 Fuse K, Kodama M, Hanawa H, Okura Y, Ito M, Shiono T, Maruyama S, Hirono S, Kato K, Watanabe K, Aizawa Y: Enhanced expression and production of monocyte chemoattractant protein-1 in myocarditis. Clin Exp Immunol 2001;124:346-352.

106 Shen Y, Xu W, Chu YW, Wang Y, Liu QS, Xiong SD: Coxsackievirus group B type 3 infection upregulates expression of monocyte chemoattractant protein 1 in cardiac myocytes, which leads to enhanced migration of mononuclear cells in viral myocarditis. J Virol 2004;78:12548-12556.

107 Cook DN, Beck MA, Coffman TM, Kirby SL, Sheridan JF, Pragnell IB, Smithies O: Requirement of MIP-1 alpha for an inflammatory response to viral infection. Science 1995;269:1583-1585.
08 Kanda T, Takahashi T: Interleukin- 6 and cardiovascular diseases. Jpn Heart J 2004; 45:183-193.

109 Kanda T, McManus JE, Nagai R, Imai S, Suzuki T, Yang D, McManus BM, Kobayashi I: Modification of viral myocarditis in mice by interleukin-6. Circ Res 1996;78:848856.

110 Tanaka T, Kanda T, McManus BM, Kanai $\mathrm{H}$, Akiyama H, Sekiguchi K, Yokoyama T, Kurabayashi M: Overexpression of interleukin- 6 aggravates viral myocarditis: impaired increase in tumor necrosis factor-alpha. J Mol Cell Cardiol 2001;33:1627-1635.

11 Serreze DV, Wasserfall C, Ottendorfer EW, Stalvey M, Pierce MA, Gauntt C, O’Donnell B, Flanagan JB, Campbell-Thompson M, Ellis TM, Atkinson MA: Diabetes acceleration or prevention by a coxsackievirus B4 infection: critical requirements for both interleukin-4 and gamma interferon. J Virol 2005;79:1045-1052.

112 Christen U, Wolfe T, Mohrle U, Hughes AC, Rodrigo E, Green EA, Flavell RA, von Herrath MG: A dual role for TNF-alpha in type 1 diabetes: islet-specific expression abrogates the ongoing autoimmune process when induced late but not early during pathogenesis. J Immunol 2001;166:70237032 .
13 Huber SA, Sartini D, Exley M: Vgamma4(+) T cells promote autoimmune CD8(+) cytolytic T-lymphocyte activation in coxsackievirus B3-induced myocarditis in mice: role for CD4(+) Th1 cells. J Virol 2002;76: 10785-10790.

114 Fairweather D, Frisancho-Kiss S, Njoku DB, Nyland JF, Kaya Z, Yusung SA, Davis SE, Frisancho JA, Barrett MA, Rose NR: Complement receptor 1 and 2 deficiency increases coxsackievirus B3-induced myocarditis, dilated cardiomyopathy, and heart failure by increasing macrophages, IL-1beta, and immune complex deposition in the heart. J Immunol 2006;176:3516-3524.

115 Rodacki M, Milech A, de Oliveira JE: NK cells and type 1 diabetes. Clin Dev Immunol 2006;13:101-107.

116 Novak J, Griseri T, Beaudoin L, Lehuen A: Regulation of type 1 diabetes by NKT cells. Int Rev Immunol 2007;26:49-72.

117 Barrat FJ, Coffman RL: Development of TLR inhibitors for the treatment of autoimmune diseases. Immunol Rev 2008;223: 271-283. 